\title{
Association of genetic polymorphisms with laryngeal carcinoma prognosis in a Chinese population
}

\author{
Fang Quan ${ }^{1, *}$, Feipeng Zhang ${ }^{1, *}$, Yanxia Bai ${ }^{1}$, Long Zhou ${ }^{2}$, Hua Yang ${ }^{3}$, Bin Li ${ }^{3}$, Tianbo \\ Jin ${ }^{3}$, Huajing $\mathbf{L i}^{1}$, Yuan Shao ${ }^{1}$ \\ ${ }^{1}$ Department of Otolaryngology \& Head Neck, The First Affiliated Hospital of Xi'an Jiaotong University, Xi'an, Shaanxi, \\ 710061, China \\ ${ }^{2}$ Sichuan Yanting Middle School, Mianyang, Sichuan, 621600, China \\ ${ }^{3}$ School of Life Sciences, Northwest University, Xi'an, Shaanxi, 710069, China \\ *These authors have contributed equally to this work \\ Correspondence to: Huajing Li, email: huajinglidoc@163.com \\ Yuan Shao, email: jiaodashaoyuan@163.com \\ Keywords: laryngeal carcinoma, single-nucleotide polymorphism, overall survival, hazard ratio
}

Received: October 20, 2016

Accepted: December 13, 2016

Published: December 30, 2016

\section{ABSTRACT}

We analyzed the effects of single-nucleotide polymorphisms (SNPs) on laryngeal carcinoma (LC) risk and overall survival (OS) in 170 Chinese male LC patients followed for $\mathbf{1 0}$ years. After assessment of clinical characteristics (age, laryngectomy, neck dissection, tumor differentiation, TNM status), the patients were genotyped for 24 SNPs associated with risk in multiple cancers. LC risk was assessed using log-rank test and Cox proportional hazard models. The median OS time was 48 months. By the follow-up deadline, OS was $41.2 \%$. Kaplan-Meier analysis indicated 1-, 3-, and 5-year survival rates to be $84.7 \%, 57.2 \%$, and $47.1 \%$, respectively. Five LC clinicopathological characteristics, namely total laryngectomy (TL), low differentiation (LD), T3-T4, N1-N2, and clinical stage III-IV were associated with worse OS (HR: 2.35, $p<0.001$; HR: 2.39, $p=0.02$; HR: 2.17, $p<$ 0.001; HR: 2.39, $p<0.001$; and HR: 3.29, $p<0.001$, respectively). Univariate cox regression analysis indicated that four SNPs were associated $(p<0.05)$ with LC OS in the codominant genetic model compared to patients with the homozygous wild-type genotype: rs10088262 G/A (HR = 1.57), rs1665650 A/G (HR = 0.65); rs3802842 $\mathrm{C} / \mathrm{C}(\mathrm{HR}=\mathbf{2 . 1 8})$, and $\mathrm{rs59336} \mathrm{T} / \mathrm{A}$ and $\mathrm{T} / \mathrm{T}(\mathrm{HR}=0.61$ and 2.61 , respectively).

\section{INTRODUCTION}

Laryngeal carcinoma (LC) is a common tumor of the head and neck. It accounts for $1 \%-5 \%$ of all malignant tumors, comprises $3.3 \%-8.1 \%$ of all the head and neck malignant tumors, and among these its incidence is only lower than that of nasopharyngeal carcinoma [1]. According to GLOBOCAN 2012 [2], 156,877 individuals were diagnosed with LC worldwide, while 20,014 cases were diagnosed in China. In this country, the age-adjusted incidence was 1.1 per 100,000 , and the age-adjusted mortality rate was 0.7 per 100,000 for both sexes. LC generally affects people aged 50-70 years, especially males. In China, the ratio of men to women diagnosed with LC was 10.5:1 $[2,3]$. In recent years, the incidence of $\mathrm{LC}$ has increased steadily because of multiple carcinogenic factors [4, 5], and in China is predicted to reach 55,900 new cases/year in the next 5 years. As with other cancers, the pathogenesis of laryngeal carcinoma involves the combined effects of environmental and genetic factors. To date, several genes have been implicated in the occurrence of LC and have been shown to affect its prognosis [6-8]. Recent studies have shown that single genes may be associated with many related cancers [9]. For example, the murine double minute 2 (MDM2) 
gene has been proposed to contribute to the emergence and development of many tumors, especially digestive carcinomas [10] and LC [1].

The association of single nucleotide polymorphisms (SNP), the most common form of genetic variation, with multiple cancers, has also been highlighted [11, 12]. While extensive studies have evaluated the relevance of clinicopathological parameters such as surgical treatment modalities, age, tumor stage, differentiation, and lymph node metastasis, as prognostic factors in head and neck cancers [13], only a few basic studies have revealed an essential role of specific genes in digestive tract cancers. Moreover, the association between SNPs within or near these genes and LC prognosis has not been fully investigated. In the present study, we analyzed the association of 24 SNPs related to digestive tract cancers with LC prognosis in 170 Han Chinese male patients, and identified four SNPs significantly associated with OS. These results shed light on the genetic component of LC and may prove useful to guide further studies addressing its pathogenesis.

\section{RESULTS}

\section{Patient, tumor, and treatment characteristics}

170 LC male patients with a mean age of 60.7 years (range, 32 to 82 years) were enrolled in this study; none of them presented distant metastases (i.e they were M0). According to primary tumor and lymph node stage, 40 cases $(23.5 \%)$ were T1, 62 cases $(36.5 \%)$ were T2, 50 cases $(29.4 \%)$ were T3, and 18 cases $(10.6 \%)$ were T4, while 116 cases $(68.2 \%)$ were N0, 30 cases $(17.6 \%)$ were N1, and 24 cases (16.1\%) were N2. Follow-up time, survival status, tumor stage and age distribution are shown in Table 1. 37 patients underwent neck dissection and 133 patients had non-neck dissection. Surgical procedures are listed in Table 2.

\section{Overall survival analysis}

At the median follow-up period of 38 months (range, 3 to 122 months), the mean and median survival times were 62.13 and 48 months, respectively. By the follow-up time deadline, OS was 41.2\% (100 dead and 70 survivors). Kaplan-Meier statistical analysis indicated that $1-, 3$-, and 5-year survival rates were $84.7 \%, 57.2 \%$ and $47.1 \%$, respectively [14].

\section{Analysis of clinical characteristics}

We performed univariate Cox proportional hazards analysis to evaluate the association of age, laryngectomy, neck dissection, differentiation, T stage,
$\mathrm{N}$ stage, and clinical stage with LC survival rates. Significant correlations were found for laryngectomy (HR: 2.35, 95\% CI: 1.58-3.49, Wald- $p<0.001$ ); tumor differentiation (HR: 2.39 , 95\%CI: 1.15-4.99, Wald- $p=$ 0.02); T stage (HR: 2.17, 95\% CI: 1.45-3.25, Wald- $p<$ 0.001 ); $\mathrm{N}$ stage (HR: 2.39 , 95\% CI: $1.58-3.62$, Wald $p$ $<0.001$ ); and clinical stage (HR: 3.29, 95\% CI: 2.105.18 , Wald- $p<0.001)$. The log-rank test further validated the significance of these five variables (Table 2). Total laryngectomy (TL) median survival time (30 months; 95\% CI: 21.32-38.68) was significantly shorter than that of partial laryngectomy (PL; 73 months; 95\% CI: 50.84-95.16; log-rank $p<0.001$ ) [14]. With respect to tumor differentiation status, a significant difference was detected between low differentiation (LD) and high differentiation (HD) groups (log-rank $p=0.008)$ : median survival time was 71 months $(95 \%$ CI: $15.55-$ 126.45) for HD, 59 months (95\% CI: 39.14-78.86) for moderate differentiation (MD), and 15 months (95\% CI: 0.00-33.33) for LD [14]. Stratification based on primary tumor staging showed a significantly longer median survival time of 77 months (95\% CI: 56.18-97.82) for T1-T2, compared to 32 months (95\% CI: 22.25-41.75) for T3-T4 (log-rank $p<0.001$ ) [14]. Lymph node staging analyses also showed a significant difference in the median survival time of N0 (71 months; 95\% CI: 48.2893.73) versus N1-N2 (26 months; 95\% CI: 14.08-37.92; log-rank $p<0.001$ ) [14]. Additionally, clinical stage (TNM status) subgroup analysis revealed a significant longer median survival time for stage I-II (98 months; 95\% CI: 67.49-128.51) compared to III-IV (32 months; 95\% CI: 24.2-39.8; log-rank $p<0.001)$ [14].

\section{SNP analysis}

In SNP univariate analyses, the lower frequency allele was coded as the 'risk' allele. All SNP genotypes were coded as 0,1 , or 2 , to represent the number of risk alleles they possessed for that SNP. The HR and $95 \%$ CI of levels 1 and 2 were compared with those for level 0 (reference genotype). Preliminary results showed significant differences for four SNPs, namely rs10088262, rs1665650, rs3802842 and rs59336 (Table 3 and Figure 1A). Among these, a significant overall effect on survival was detected for three SNPs. The median survival times for patients with rs 1665650 genotypes 0,1 or 2 were 36,71 , and 18 months $\left(\chi^{2}=18.96\right.$, log-rank $\left.p<0.001\right)$ respectively (Figure $1 \mathrm{~B}$ ); for rs3802842 genotypes 0,1 or 2 , median survival times were 48,68 , and 26 months $\left(\chi^{2}=10.06\right.$, logrank $p=0.007$ ) respectively (Figure 1C); for rs59336 genotypes 0,1 or 2 , median survival times were 36,68 , 12 months $\left(\chi^{2}=15.21\right.$, log-rank $\left.p<0.001\right)$ respectively (Figure 1D). 
Table 1: Clinicopathological characteristics of the patients included in this study

\begin{tabular}{|c|c|c|}
\hline Patient Characteristics & No. & $\%$ \\
\hline Total & $170\left(\right.$ male, $\left.\mathrm{M} 0^{\mathrm{c}}\right)$ & 100 \\
\hline Min follow-up time (month) & 3 & - \\
\hline Max follow-up time (month) & 122 & - \\
\hline Median follow-up time (month) & 38 & - \\
\hline Survival status & 70 survivors & 41.2 \\
\hline 100 dead & 58.8 & \\
\hline Mean Age & 60.75 & \\
\hline Range & $32-82$ & \\
\hline$<60$ & 80 & 47.1 \\
\hline$\geq 60$ & 90 & 52.9 \\
\hline \multicolumn{3}{|l|}{ Tumor Stage ${ }^{a}$} \\
\hline $\mathrm{T} 1$ & 40 & 23.5 \\
\hline $\mathrm{T} 2$ & 62 & 36.5 \\
\hline $\mathrm{T} 3$ & 50 & 29.4 \\
\hline $\mathrm{T} 4$ & 18 & 10.6 \\
\hline N0 & 116 & 68.2 \\
\hline N1 & 30 & 17.6 \\
\hline $\mathrm{N} 2$ & 24 & 14.1 \\
\hline \multicolumn{3}{|l|}{ Clinical Stage $^{b}$} \\
\hline I & 37 & 21.8 \\
\hline II & 36 & 21.2 \\
\hline III & 61 & 35.9 \\
\hline IV & 36 & 21.2 \\
\hline \multicolumn{3}{|l|}{ Differentiation degree } \\
\hline Low & 14 & 8.2 \\
\hline Moderate & 125 & 73.5 \\
\hline High & 31 & 18.2 \\
\hline \multicolumn{3}{|l|}{ Merged Surgical Procedures } \\
\hline Neck Dissection & 37 & 21.8 \\
\hline Non-Neck Dissection & 133 & 78.2 \\
\hline
\end{tabular}

a: T-stage: tumor stage; N-stage: lymph node stage

b: Clinical stage reference: international unifying new TNM classification from Union for International Cancer Control c: M0: No distant metastasis; 
Table 2: Univariate Cox proportional hazards analysis of potential factors affecting survival

\begin{tabular}{|c|c|c|c|c|c|c|c|c|c|c|}
\hline \multirow[t]{2}{*}{ Variable } & \multirow[t]{2}{*}{ Wald } & \multirow[t]{2}{*}{ HR (95\% CI) } & \multirow[t]{2}{*}{$\mathbf{p}^{a}$} & \multirow[t]{2}{*}{ Details } & \multicolumn{2}{|c|}{ Median } & \multirow{2}{*}{$\begin{array}{l}1-, 3-, 5 \text {-year } \\
\text { survival rate }\end{array}$} & \multicolumn{3}{|c|}{ Overall comparison } \\
\hline & & & & & Estimate & $95 \% \mathrm{CI}$ & & $\begin{array}{c}\text { Chi- } \\
\text { Square }\end{array}$ & df & $\begin{array}{c}p^{b} \text { for } \\
\text { log-rank }\end{array}$ \\
\hline Total & & & & & 48.00 & $29.26-66.74$ & $0.929,0.788,0.671$ & & & \\
\hline \multirow[t]{2}{*}{ Age } & 0.55 & $1.16(0.78-1.72)$ & 0.460 & $<60$ & 59.00 & $30.05-87.95$ & $0.85,0.584,0.414$ & & & \\
\hline & & & & $\geq 60$ & 48.00 & $29.86-66.14$ & $0.867,0.633,0.507$ & 0.556 & 1 & 0.456 \\
\hline \multirow[t]{2}{*}{ Laryngectomy } & 17.64 & $2.35(1.58-3.49)$ & $<0.001 *$ & PL & 73.00 & $50.84-95.16$ & $0.885,0.73,0.632$ & & & \\
\hline & & & & $\mathrm{TL}$ & 30.00 & $21.32-38.68$ & $0.818,0.468,0.27$ & 18.96 & 1 & $<0.001 *$ \\
\hline \multirow{2}{*}{$\begin{array}{l}\text { Neck } \\
\text { dissection }\end{array}$} & 1.69 & $0.71(0.43-1.19)$ & 0.194 & ND & 36.00 & - & $0.676,-,-$ & & & \\
\hline & & & & NND & 56.00 & $36.32-75.69$ & $0.91,0.752,0.583$ & 1.73 & 1 & 0.188 \\
\hline \multirow[t]{3}{*}{ Differentiation } & 8.99 & & $0.011 *$ & HD & 71.00 & $15.55-126.45$ & $0.676,-,-$ & & & \\
\hline & 0.07 & $0.93(0.57-1.57)$ & 0.794 & MD & 59.00 & $39.14-78.86$ & $0.912,0.712,0.602$ & & & \\
\hline & 5.44 & $2.39(1.15-4.99)$ & $0.02 *$ & LD & 15.00 & $0.00-33.33$ & $0.214,-,-$ & 9.78 & 2 & $0.008^{*}$ \\
\hline \multirow[t]{2}{*}{$\mathrm{T}$} & 14.07 & $2.17(1.45-3.25)$ & $<0.001^{*}$ & $\mathrm{~T} 1-\mathrm{T} 2$ & 77.00 & $56.18-97.82$ & $0.882,0.695,0.616$ & & & \\
\hline & & & & T3-T4 & 32.00 & $22.25-41.75$ & $0.824,0.483,0.243$ & 14.96 & 1 & $<0.001^{*}$ \\
\hline \multirow[t]{2}{*}{$\mathrm{N}$} & 17.04 & $2.39(1.58-3.62)$ & $<0.001 *$ & No & 71.00 & $48.28-93.73$ & $0.897,0.706,0.6$ & & & \\
\hline & & & & N1-N2 & 26.00 & $14.08-37.92$ & $0.796,0.403,-$ & 18.33 & 1 & $<0.001 *$ \\
\hline \multirow[t]{2}{*}{ Clinical stage } & 26.86 & $3.29(2.10-5.18)$ & $<0.001^{*}$ & I-II & 98.00 & $67.49-128.51$ & $0.849,0.732,0.527$ & & & \\
\hline & & & & III, IV & 32.00 & $24.2-39.8$ & $0.897,0.649,0.418$ & 30.15 & 1 & $<0.001^{*}$ \\
\hline
\end{tabular}

a. $p$ for Wald test $<0.05$ indicates statistical significance for individual coefficients

b. $p$ for Log-rank Test $<0.05$ indicates statistical significance for grouping variables

Abbreviations: PL: Partial laryngectomy; TL: Total laryngectomy; ND: Neck dissection; NND: Non-neck dissection; HD:

High differentiation; MD: Moderate differentiation; LD: Low differentiation; df: degrees of freedom. *: indicates statistical significance

\section{Multivariate Cox proportional hazards analysis}

We performed multivariate Cox regression analysis by including the five clinical predictors that showed statistical significance in univariate analyses. Results indicated that two SNPs (rs10088262 and rs3802842) correlated significantly with OS in LC patients: compared with "GG" in rs 10088262 , the risk rate of genotype "G/A" was 1.969 (95\% CI: 1.26-3.09, $p=0.003)$; on the other hand, the risk rate of rs3802842 (C/C vs. A/A) was 1.839 (95\% CI: 1.10-3.08, $p=0.021$ ) (Table 4).

\section{DISCUSSION}

Our study analyzed, during a ten-year follow-up, the prognostic association of clinical parameters and multiple cancer-related SNPs in 170 male LC patients from northwest China. We found that five clinical characteristics [laryngectomy, tumor differentiation, tumor status $(\mathrm{T})$, regional lymph node status $(\mathrm{N})$, and clinical (TNM) stage] were correlated with survival. Specifically, clinical outcome was affected by laryngectomy variants, as TL had poorer prognosis than PL, with a median survival of 30 months, compared with 73 months for PL. This conclusion, however, may be confounded by the fact that TL is more often performed to remove larger malignant tumors, which carry higher risk. The associations found for other clinical features were consistent with the findings of previous studies, as low tumor differentiation, and higher T, N, and clinical stages all correlated with worse prognoses $[15,16]$.

Of the 24 SNPs analyzed, four showed an association with LC prognosis in univariate analyses. After adjusting for significant clinical parameters, multivariate regression analysis revealed that two SNP genotypes, i.e. "G/A" of rs10088262 (HR: 1.969) and "C/C" of rs3802842 (HR: 1.839) were significantly associated with LC prognosis. The SNPs analyzed here have been shown to be associated with risk for diverse 
Table 3: Analysis of SNPs associated with OS in LC patients

\begin{tabular}{|c|c|c|c|c|c|c|c|c|c|c|}
\hline \multirow[t]{2}{*}{ SNP } & \multirow[t]{2}{*}{ Genotype } & \multirow[t]{2}{*}{ Total N } & \multicolumn{4}{|c|}{ Variables in the Equation } & \multirow[t]{2}{*}{ Median } & \multirow[t]{2}{*}{$95 \% \mathrm{CI}$} & \multicolumn{2}{|c|}{ Chi-Square $p^{\mathrm{b}}$ for log-rank } \\
\hline & & & Wald & HR & $95 \%$ CI & $p^{\text {a }}$ & & & & \\
\hline \multirow[t]{4}{*}{ rs 10088262} & $\mathrm{G} / \mathrm{G}(0)$ & 55 & 4.69 & & & 0.096 & 66.00 & $39.47-92.53$ & & \\
\hline & G/A (1) & 71 & 4.38 & 1.57 & $1.03-2.39$ & $0.036^{*}$ & 32.00 & $22.64-41.36$ & & \\
\hline & $\mathrm{A} / \mathrm{A}(2)$ & 34 & 0.76 & 1.57 & $0.57-4.34$ & 0.382 & 32.00 & $0-87.21$ & & \\
\hline & Overall & 160 & & & & & 48.00 & $30.56-65.44$ & 4.84 & 0.809 \\
\hline \multirow[t]{4}{*}{ rs 1665650} & $\mathrm{G} / \mathrm{G}(0)$ & 52 & 7.99 & & & $0.018^{*}$ & 36.00 & $25.73-46.27$ & & \\
\hline & $\mathrm{A} / \mathrm{G}(1)$ & 107 & 3.95 & 0.65 & $0.43-0.99$ & $0.047^{*}$ & 71.00 & $49.22-92.78$ & & \\
\hline & $\mathrm{A} / \mathrm{A}(2)$ & 7 & 2.00 & 1.98 & $0.77-5.09$ & 0.157 & 18.00 & $0.04-35.94$ & & \\
\hline & Overall & 166 & & & & & 48.00 & $30.54-65.46$ & 8.56 & $0.014 *$ \\
\hline \multirow[t]{4}{*}{ rs 3802842} & $\mathrm{~A} / \mathrm{A}(0)$ & 112 & 9.44 & & & $0.009^{*}$ & 48.00 & $18.72-77.29$ & & \\
\hline & $\mathrm{C} / \mathrm{A}(1)$ & 32 & 0.01 & 1.02 & $0.60-1.73$ & 0.939 & 68.00 & $31.09-104.91$ & & \\
\hline & $\mathrm{C} / \mathrm{C}(2)$ & 24 & 9.03 & 2.18 & $1.31-3.61$ & $0.003^{*}$ & 26.00 & $9.00-43.00$ & & \\
\hline & Overall & 168 & & & & & 50.00 & $31.06-68.94$ & 10.06 & $0.007 *$ \\
\hline \multirow[t]{4}{*}{ rs59336 } & $\mathrm{A} / \mathrm{A}(0)$ & 30 & 13.3 & & & $0.001 *$ & 36.00 & $30.31-41.69$ & & \\
\hline & T/A (1) & 115 & 4.09 & 0.61 & $0.37-.985$ & $0.043^{*}$ & 68.00 & $38.56-97.44$ & & \\
\hline & $\mathrm{T} / \mathrm{T}(2)$ & 7 & 4.28 & 2.61 & $1.05-6.49$ & $0.039 *$ & 12.00 & $9.43-14.57$ & & \\
\hline & Overall & 152 & & & & & 46.00 & $27.65-64.35$ & 15.21 & $<0.001 *$ \\
\hline
\end{tabular}

$p^{\text {a }}$ for Wald test $<0.05$ indicates statistical significance for individual coefficients

$p^{\mathrm{b}}$ for Log-rank Test $<0.05$ indicates statistical significance for grouping variables

*: indicates statistical significance
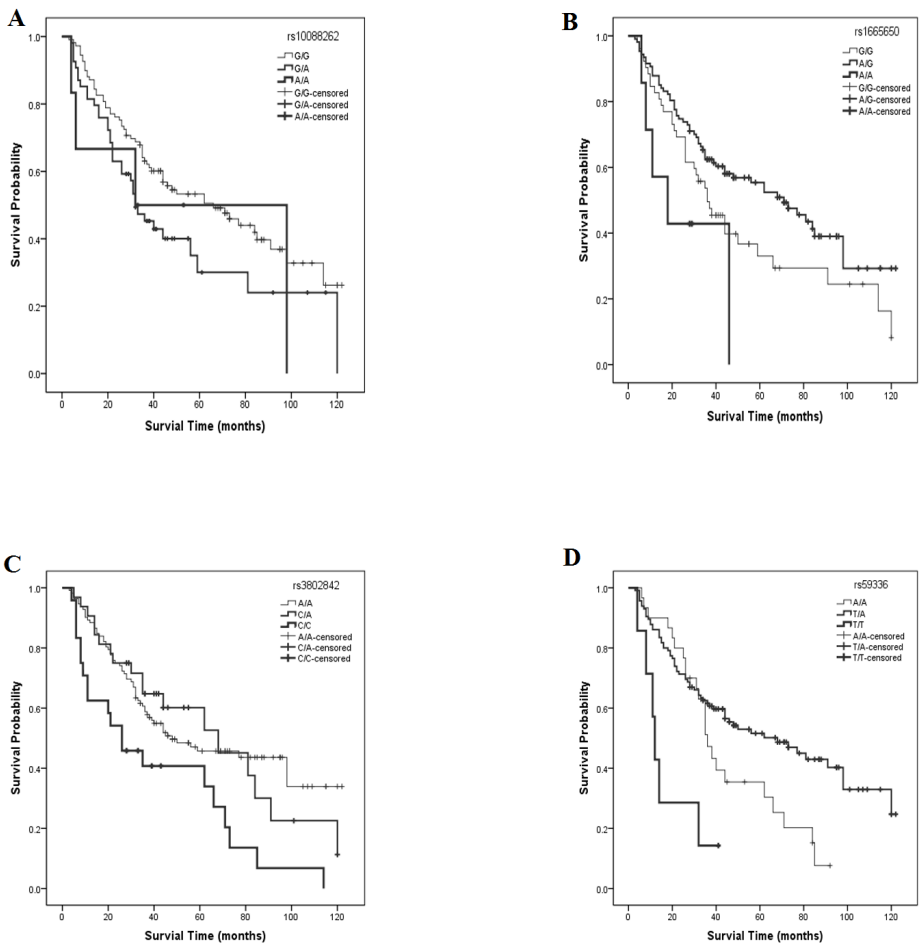

Figure 1: Survival rate curves for different SNP polymorphisms. 
Table 4: Multivariate Cox proportional hazards analysis of rs10088262 and rs3802842 adjusted for HD, MD, LD, T stage and clinical stage

\begin{tabular}{lcccccc}
\hline SNP & Variable & Wald & df & HR & 95\% CI & $\boldsymbol{p}^{\text {a }}$ \\
\hline rs10088262 & rs10088262(G/G) & 8.853 & 2 & & & $0.012^{*}$ \\
& rs10088262(G/A) & 8.719 & 1 & 1.969 & $1.26-3.09$ & $0.003 *$ \\
& rs10088262(A/A) & 0.661 & 1 & 1.534 & $0.55-4.29$ & 0.416 \\
rs3802842 & rs3802842(A/A) & 7.014 & 2 & & $0.030^{*}$ \\
& rs3802842(C/A) & 0.510 & 1 & 0.820 & $0.48-1.41$ & 0.475 \\
& rs3802842(C/C) & 5.353 & 1 & 1.839 & $1.10-3.08$ & $0.021 *$ \\
\hline
\end{tabular}

Abbreviations: HD: High differentiation; MD: Moderate differentiation; LD: Low differentiation; df: degrees of freedom *: indicates statistical significance.

Table 5: SNPs analyzed

\begin{tabular}{|c|c|c|c|c|c|}
\hline SNP & Band & $\mathbf{A} / \mathbf{B}$ & Gene & Cancer type & Ref \\
\hline rs2439302 & $8 \mathrm{p} 12$ & $\mathrm{C} / \mathrm{G}$ & $N R G 1$ & Thyroid & {$[22]$} \\
\hline rs7832232 & $8 \mathrm{p} 11.22$ & $\mathrm{G} / \mathrm{A}$ & intergenic & Pancreatic & {$[23]$} \\
\hline rs10088262 & $8 \mathrm{q} 24.13$ & $\mathrm{~A} / \mathrm{G}$ & intergenic & Esophageal & {$[12]$} \\
\hline rs 10505477 & $8 \mathrm{q} 24.21$ & $\mathrm{~T} / \mathrm{C}$ & intergenic & Gastric & {$[24]$} \\
\hline rs6983267 & $8 \mathrm{q} 24.21$ & $\mathrm{G} / \mathrm{T}$ & intergenic & Prostate & {$[25]$} \\
\hline rs 7014346 & $8 \mathrm{q} 24.21$ & $\mathrm{~A} / \mathrm{G}$ & POU5F1B & Colorectal & {$[26]$} \\
\hline rs13294589 & $9 \mathrm{p} 21.2$ & $\mathrm{G} / \mathrm{A}$ & intergenic & Esophageal & {$[12]$} \\
\hline rs10114408 & $9 \mathrm{q} 22.32$ & $\mathrm{~T} / \mathrm{A}$ & intergenic & Colorectal & {$[27]$} \\
\hline rs965513 & $9 \mathrm{q} 22.33$ & $\mathrm{~A} / \mathrm{G}$ & intergenic & Thyroid & {$[22]$} \\
\hline rs10795668 & 10p14 & $\mathrm{A} / \mathrm{G}$ & intergenic & Colorectal & {$[28]$} \\
\hline rs2274223 & $10 \mathrm{q} 23.33$ & $\mathrm{G} / \mathrm{A}$ & PLCE1 & Esophageal & [29] \\
\hline rs 1665650 & $10 \mathrm{q} 25.3$ & $\mathrm{~A} / \mathrm{G}$ & HSPA12A & Colorectal & {$[30]$} \\
\hline rs 12413624 & $10 \mathrm{q} 26.11$ & $\mathrm{~T} / \mathrm{A}$ & intergenic & Colorectal/Gastric & {$[31]$} \\
\hline rs10500715 & $11 \mathrm{p} 15.4$ & $\mathrm{G} / \mathrm{T}$ & $S B F 2$ & Pancreatic & {$[32]$} \\
\hline rs3824999 & $11 \mathrm{q} 13.4$ & $\mathrm{C} / \mathrm{A}$ & POLD3 & Colorectal & [33] \\
\hline rs3802842 & $11 \mathrm{q} 23.1$ & $\mathrm{~A} / \mathrm{C}$ & C11orf92-C11orf93 & Colorectal & [18] \\
\hline rs 10774214 & $12 \mathrm{p} 13.32$ & $\mathrm{~T} / \mathrm{C}$ & intergenic & Colorectal & [34] \\
\hline rs3217901 & $12 \mathrm{p} 13.32$ & $\mathrm{~A} / \mathrm{G}$ & CCND2 & Colorectal & {$[34]$} \\
\hline rs 10879357 & $12 \mathrm{q} 21.1$ & $\mathrm{G} / \mathrm{A}$ & ТРH2 & Colorectal & [34] \\
\hline rs671 & $12 q 24.12$ & $\mathrm{~A} / \mathrm{G}$ & $A L D H 2$ & Esophageal & {$[35]$} \\
\hline rs4767364 & $12 q 24.13$ & $\mathrm{G} / \mathrm{A}$ & NAA25 & Aero-digestive tract & {$[36]$} \\
\hline rs 11066280 & $12 \mathrm{q} 24.13$ & $\mathrm{~A} / \mathrm{T}$ & C12orf51 & Gastric & [37] \\
\hline rs59336 & $12 q 24.21$ & $\mathrm{~T} / \mathrm{A}$ & $T B X 3$ & Colorectal & {$[34]$} \\
\hline rs7315438 & $12 \mathrm{q} 24.21$ & $\mathrm{~T} / \mathrm{C}$ & intergenic & Colorectal/ Esophageal & {$[38]$} \\
\hline
\end{tabular}

A/B stands for minor/major alleles on the sample frequencies. 
types of cancer. Rs 10088262 is an intergenic variant located on chromosome 8q24.13; its minor allele "A" has been correlated with reduced risk of esophageal cancer [12]. However, in the present study the genotype "G/A" of this SNP indicated poor prognosis, with a median survival time of 32 months, compared with 66 months for the "G/G" genotype.

Carrying the "C" allele at rs3802842 has been associated with a lower risk for rectal tumors [17]. Another study, however, suggested that the "CC" genotype of rs3802842 may significantly increase colorectal cancer (CRC) risk in the recessive model [18]. Our analysis revealed that the median survival of genotype "C/C" of the rs3802842 polymorphism was only 26 months, significantly less than the homozygous wild genotype "A/A" (48 months). Rs3802842 maps to a region between "colorectal cancer associated 1" and "colorectal cancer associated 2" (C11 orf92/COLCA1C11orf93/COLCA2) genes, located on 11q23.1, which are arranged on opposite strands and share a regulatory region that contains genetic variants that are in high linkage disequilibrium with rs3802842. Expression levels of COLCA1 and COLCA2 transcripts correlate with rs3802842 genotypes. Genetic, expression and immunohistochemical data implicate COLCA1 and $C O L C A 2$ in the pathogenesis of colon cancer, whereas histologic analyses indicate the involvement of immune pathways [19].

\section{MATERIALS AND METHODS}

\section{Patients and methods}

\section{Study population}

170 male patients, aged 32-82 years (average age, 60.7 years), were enrolled at the First Affiliated Hospital of Xi'an Jiao Tong University from January 30, 2002 to April 7, 2003; patient follow-up ended on April 7, 2013. Patients received neither radiotherapy nor chemotherapy before enrollment, and in all cases LC diagnosis was confirmed by two pathologists. All participants were unrelated Han Chinese and had no other malignancy histories.

\section{Patient demographics and blood collection}

A standardized epidemiological questionnaire including residential region, age, smoking status, alcohol use, ethnicity, education status, and family history of cancer was used to collect personal information through in-person interviews. Related information was collected through a consultation with the treating physicians or from medical chart reviews. LC staging relies on the TNM system designed jointly by the Union International Cancer Control Version 7.0 (UICC 7.0). Venous blood samples $(5 \mathrm{ml})$ and signed informed consent were obtained from each participant. All blood samples were quickly frozen in liquid nitrogen and stored at $-80^{\circ} \mathrm{C}$. This study was approved by the ethics committee of the First Affiliated Hospital of Xi'an Jiao Tong University.

\section{SNP selection and genotyping}

Using the HapMap database, 24 candidate SNPs with minor allele frequencies $>5 \%$ in the Asian population and previously published associations with other cancers were selected from chromosomes 8, 9, 10, 11, and 12 . Basic information about the 24 SNPs is listed in Table 5. Genomic DNA was extracted from peripheral blood using phenol-chloroform, and its concentration was measured using a DU530 UV/VIS spectrophotometer (Beckman Instruments, Fullerton, CA, USA) according to the manufacturer's protocol. MassARRAY Assay Design 3.0 Software (Sequenom, San Diego, California, USA) was used to design Multiplex SNP MassEXTEND assays[20]. Genotyping was performed using the Sequenom MassARRAY RS1000 following a standard protocol recommended by the manufacturer [20], and data were analyzed using Sequenom Typer 4.0 Software (Sequenom, San Diego, CA, USA) [20, 21].

\section{Statistical analysis}

Patients' baseline characteristics, disease stage, and treatment modalities were summarized using descriptive statistics. The overall survival (OS) time was defined as the period from diagnosis until death of any cause or until the date of the last follow-up, at which data point was censored. All summary statistics on time-to-event variables were estimated according to the Kaplan-Meier method and compared using the log-rank test. Univariate and multivariate Cox proportional hazards regression models were used to calculate the hazard ratios (HR), and $95 \%$ confidence intervals $(95 \% \mathrm{CI})$ of the effect of clinical variables and SNPs, respectively, on the overall survival (OS) of LC patients. SPSS software (version 21.0) was used for statistical analysis. A $p$ value $<0.05$ was considered significant.

\section{CONCLUSION}

We found that five clinicopathological characteristics, namely total laryngectomy, low differentiation, T3-T4, N1-N2, and clinical stage III-IV, were associated with survival in LC patients. Although four SNP were found to be significantly associated with OS in univariate cox regression analysis, multivariate analysis showed that two SNPs (rs10088262 and rs3802842) were associated with LC prognosis after adjustment for clinical factors. Combined with previous research, our study suggests an association for these SNPs with multiple cancers. Further larger studies are required to validate our findings and to assess the molecular mechanisms underlying the observed associations. 


\section{ACKNOWLEDGMENTS}

This study was funded by the China Postdoctoral Science Foundation (NO. 2015M572575) and Key Science and Technology Program of Shaanxi Province, China (NO. 2014K11-01-01-09). We are grateful to the patients for their participation in this study. We also thank the clinicians and hospital staff who contributed to the sample and data collection for this study.

\section{CONFLICTS OF INTEREST}

All authors declare that they have no conflicts of interest.

\section{REFERENCES}

1. Wang $\mathrm{H}$ and Ma K. Association between MDM2 rs769412 and rs937283 polymorphisms with alcohol drinking and laryngeal carcinoma risk. International journal of clinical and experimental pathology. 2015; 8:7436-7440.

2. Ferlay J, Soerjomataram I, Dikshit R, Eser S, Mathers C, Rebelo M, Parkin DM, Forman D and Bray F. Cancer incidence and mortality worldwide: sources, methods and major patterns in GLOBOCAN 2012. International journal of cancer. 2015; 136:E359-386.

3. Bray F, Ren JS, Masuyer E and Ferlay J. Global estimates of cancer prevalence for 27 sites in the adult population in 2008. International journal of cancer. 2013; 132:1133-1145.

4. Leon X, Quer M, Diez S, Orus C, Lopez-Pousa A and Burgues J. Second neoplasm in patients with head and neck cancer. Head \& neck. 1999; 21:204-210.

5. Mallis A, Jelastopulu E, Mastronikolis NS, Naxakis SS, Kourousis C and Papadas TA. Laryngeal cancer and passive smoking: the neglected factor? European archives of oto-rhinolaryngology. 2011; 268:727-731.

6. Simsek H, Han U, Onal B and Simisek G. The expression of EGFR, cerbB2, p16, and p53 and their relationship with conventional parameters in squamous cell carcinoma of the larynx. Turkish journal of medical sciences. 2014; 44:411-416.

7. Shen Z, Zhan G, Deng H, Kang C and Guo J. Growth inhibitory effect of microRNA-519b-3p on larynx squamous Hep-2 cells. [Article in Chinese]. Zhonghua er bi yan hou tou jing wai ke za zhi. 2014; 49:151-156.

8. Chai D, Bao Z, Hu J, Ma L, Feng Z and Tao Y. Aberrant expression of CyclinE and p27 in laryngeal squamous cell carcinoma and the clinical significance. [Article in Chinese]. Lin chuang er bi yan hou tou jing wai ke za zhi. 2014; 28:165-169, 174.

9. Lu C, Xie M, Wendl MC, Wang J, McLellan MD, Leiserson MD, Huang KL, Wyczalkowski MA, Jayasinghe R, Banerjee T, Ning J, Tripathi P, Zhang Q, Niu B, Ye K, Schmidt HK, et al. Patterns and functional implications of rare germline variants across 12 cancer types. Nature communications. 2015; 6:10086.

10. Abderrahmane R, Louhibi L, Moghtit FZ, Boubekeur A, Benseddik K, Boudjema A, Benrrahal F, Aberkane M, Fodil M and Saidi-Mehtar N. TP53 Arg 72Pro and MDM2 SNP309 polymorphisms and colorectal cancer risk: a west Algerian population study. Pathology oncology research. 2015; 21:629-635.

11. Ek WE, Levine DM, D’Amato M, Pedersen NL, Magnusson PK, Bresso F, Onstad LE, Schmidt PT, Tornblom H, Nordenstedt H, Romero Y, Mayo Clinic Esophageal A, Barrett's Esophagus Registry C, Chow WH, Murray LJ, Gammon MD, et al. Germline genetic contributions to risk for esophageal adenocarcinoma, Barrett's esophagus, and gastroesophageal reflux. Journal of the National Cancer Institute. 2013; 105:1711-1718.

12. Wang J, Zhang B, Yang Z, Zhou L, Geng T, Li H, Fu X, Xue X, Liu M, Tong R, Jin T and Zhang Y. Association of gastrointestinal gland cancer susceptibility loci with esophageal carcinoma among the Chinese Han population: a case-control study. Tumour biology. 2015.

13. Leoncini E, Vukovic V, Cadoni G, Pastorino R, Arzani D, Bosetti C, Canova C, Garavello W, La Vecchia C, Maule M, Petrelli L, Pira E, Polesel J, Richiardi L, Serraino D, Simonato L, et al. Clinical features and prognostic factors in patients with head and neck cancer: Results from a multicentric study. Cancer epidemiology. 2015; 39:367-374.

14. Shen Z, Ren W, Bai Y, Chen Z, Li J, Li B, Jin T, Cao P and Shao Y. DIRC3 and near NABP1 genetic polymorphisms are associated laryngeal squamous cell carcinoma patient survival. Oncotarget. 2016; 7:79596-04. doi: 10.18632/ oncotarget. 12865 .

15. Bice TC, Tran V, Merkley MA, Newlands SD, van der Sloot PG, Wu S and Miller MC. Disease-Specific Survival with Spindle Cell Carcinoma of the Head and Neck. Otolaryngology--head and neck surgery. 2015; 153:973-980.

16. Dubal PM, Unsal AA, Echanique KA, Vazquez A, Reder LS, Baredes S and Eloy JA. Laryngeal adenosquamous carcinoma: A population-based perspective. The Laryngoscope. 2015.

17. Mates IN, Jinga V, Csiki IE, Mates D, Dinu D, Constantin A and Jinga M. Single nucleotide polymorphisms in colorectal cancer: associations with tumor site and TNM stage. Journal of gastrointestinal and liver diseases. 2012; 21:45-52.

18. Duan X, Li X, Lou H, Geng T, Jin T, Liang P, Li S, Long $\mathrm{Y}$ and Chen C. Genetic association of PLCE1, C11orf92C11orf93, and NOC3L with colorectal cancer risk in the Han population. Tumour biology. 2014; 35:1813-1817.

19. Peltekova VD, Lemire M, Qazi AM, Zaidi SH, Trinh QM, Bielecki R, Rogers M, Hodgson L, Wang M, D’Souza DJ, Zandi S, Chong T, Kwan JY, Kozak K, De Borja R, Timms L, et al. Identification of genes expressed by immune cells of the colon that are regulated by colorectal 
cancer-associated variants. International journal of cancer. 2014; 134:2330-2341.

20. Gabriel S, Ziaugra L and Tabbaa D. SNP genotyping using the Sequenom MassARRAY iPLEX platform. Current protocols in human genetics. 2009; Chapter 2:Unit 212.

21. Thomas RK, Baker AC, Debiasi RM, Winckler W, Laframboise T, Lin WM, Wang M, Feng W, Zander T, MacConaill L, Lee JC, Nicoletti R, Hatton C, Goyette M, Girard L, Majmudar K, et al. High-throughput oncogene mutation profiling in human cancer. Nature genetics. 2007; 39:347-351.

22. Wang YL, Feng SH, Guo SC, Wei WJ, Li DS, Wang Y, Wang X, Wang ZY, Ma YY, Jin L, Ji QH and Wang JC. Confirmation of papillary thyroid cancer susceptibility loci identified by genome-wide association studies of chromosomes 14q13, 9q22, 2q35 and $8 \mathrm{p} 12$ in a Chinese population. Journal of medical genetics. 2013; 50:689-695.

23. Low SK, Kuchiba A, Zembutsu H, Saito A, Takahashi A, Kubo M, Daigo Y, Kamatani N, Chiku S, Totsuka H, Ohnami S, Hirose H, Shimada K, Okusaka T, Yoshida T, Nakamura Y, et al. Genome-wide association study of pancreatic cancer in Japanese population. PloS one. 2010; 5:e11824.

24. Shen L, Du M, Wang C, Gu D, Wang M, Zhang Q, Zhao T, Zhang X, Tan Y, Huo X, Gong W, Xu Z, Chen J and Zhang Z. Clinical significance of POU5F1P1 rs10505477 polymorphism in Chinese gastric cancer patients receving cisplatin-based chemotherapy after surgical resection. International journal of molecular sciences. 2014; 15:12764-12777.

25. Fernandez P, Salie M, du Toit D and van der Merwe A. Analysis of Prostate Cancer Susceptibility Variants in South African Men: Replicating Associations on Chromosomes 8q24 and 10q11. Prostate cancer. 2015; 2015:465184.

26. Wei W, Jiang M, Luo L, Li Z, Wang P and Dong WQ. Colorectal cancer susceptibility variants alter risk of breast cancer in a Chinese Han population. Genetics and molecular research. 2013; 12:6268-6274.

27. Jiao S, Hsu L, Berndt S, Bezieau S, Brenner H, Buchanan D, Caan BJ, Campbell PT, Carlson CS, Casey G, Chan AT, Chang-Claude J, Chanock S, Conti DV, Curtis KR, Duggan $\mathrm{D}$, et al. Genome-wide search for gene-gene interactions in colorectal cancer. PloS one. 2012; 7:e52535.

28. Li FX, Yang XX, Hu NY, Du HY, Ma Q and Li M. Singlenucleotide polymorphism associations for colorectal cancer in southern chinese population. Chinese journal of cancer research. 2012; 24:29-35.

29. Chen YZ, Cui XB, Pang XL, Li L, Hu JM, Liu CX, Cao YW, Yang L and Li F. Relationship between rs2274223 and rs3765524 polymorphisms of PLCE1 and risk of esophageal squamous cell carcinoma in a Kazakh Chinese population.
[Article in Chinese]. Zhonghua bing li xue za zhi. 2013; 42:795-800.

30. Kantor ED, Hutter CM, Minnier J, Berndt SI, Brenner H, Caan BJ, Campbell PT, Carlson CS, Casey G, Chan AT, Chang-Claude J, Chanock SJ, Cotterchio M, Du M, Duggan D, Fuchs CS, et al. Gene-environment interaction involving recently identified colorectal cancer susceptibility Loci. Cancer epidemiology, biomarkers \& prevention. 2014; 23:1824-1833.

31. Su Q, Wang Y, Zhao J, Ma C, Wu T, Jin T and Xu J. Polymorphisms of PRLHR and HSPA12A and risk of gastric and colorectal cancer in the Chinese Han population. BMC gastroenterology. 2015; 15:107.

32. Wu C, Kraft P, Stolzenberg-Solomon R, Steplowski E, Brotzman M, Xu M, Mudgal P, Amundadottir L, Arslan AA, Bueno-de-Mesquita HB, Gross M, Helzlsouer K, Jacobs EJ, Kooperberg C, Petersen GM, Zheng W, et al. Genome-wide association study of survival in patients with pancreatic adenocarcinoma. Gut. 2014; 63:152-160.

33. Dunlop MG, Dobbins SE, Farrington SM, Jones AM, Palles C, Whiffin N, Tenesa A, Spain S, Broderick P, Ooi LY, Domingo E, Smillie C, Henrion M, Frampton M, Martin L, Grimes $\mathrm{G}$, et al. Common variation near CDKN1A, POLD3 and SHROOM2 influences colorectal cancer risk. Nature genetics. 2012; 44:770-776.

34. Jia WH, Zhang B, Matsuo K, Shin A, Xiang YB, Jee SH, Kim DH, Ren Z, Cai Q, Long J, Shi J, Wen W, Yang G, Delahanty RJ, Genetics, Epidemiology of Colorectal Cancer $\mathrm{C}$, et al. Genome-wide association analyses in East Asians identify new susceptibility loci for colorectal cancer. Nature genetics. 2013; 45:191-196.

35. Zhao T, Wang C, Shen L, Gu D, Xu Z, Zhang X, Xu Y and Chen J. Clinical significance of ALDH2 rs671 polymorphism in esophageal cancer: evidence from 31 case-control studies. OncoTargets and therapy. 2015; 8:649-659.

36. McKay JD, Truong T, Gaborieau V, Chabrier A, Chuang SC, Byrnes G, Zaridze D, Shangina O, Szeszenia-Dabrowska N, Lissowska J, Rudnai P, Fabianova E, Bucur A, Bencko V, Holcatova I, Janout V, et al. A genome-wide association study of upper aerodigestive tract cancers conducted within the INHANCE consortium. PLoS genetics. 2011; 7:e1001333.

37. Zhang G, Gu D, Zhao Q, Chu H, Xu Z, Wang M, Tang C, Wu D, Tong N, Gong W, Zhou J, Xu Y, Zhang Z and Chen J. Genetic variation in C12orf51 is associated with prognosis of intestinal-type gastric cancer in a Chinese population. Biomedicine \& pharmacotherapy. 2015; 69:133-138.

38. Geng TT, Xun XJ, Li S, Feng T, Wang LP, Jin TB and Hou P. Association of colorectal cancer susceptibility variants with esophageal cancer in a Chinese population. World journal of gastroenterology. 2015; 21:6898-6904. 